\title{
Processing of Fecal Sludge to Fertilizer Pellets Using a Low-Cost Technology in Ghana
}

\author{
Josiane Nikiema ${ }^{1}$, Olufunke Cofie ${ }^{1}$, Robert Impraim ${ }^{1} \&$ Noah Adamtey ${ }^{2}$ \\ ${ }^{1}$ International Water Management Institute, Cantonments, Accra, Ghana \\ ${ }^{2}$ Biotechnology and Nuclear Agriculture Research Institute, Legon, Accra, Ghana \\ Correspondence: Josiane Nikiema, International Water Management Institute, P.M.B. CT 112, Cantonments, \\ Accra, Ghana. Tel: 233-302-784-753/754. E-mail: J.Nikiema@cgiar.org
}

Received: July 16, $2013 \quad$ Accepted: August 27, $2013 \quad$ Online Published: September 6, 2013
doi:10.5539/ep.v2n4p70

\begin{abstract}
This paper describes a study that was aimed at optimizing the pelletization of fecal sludge-based fertilizers for agricultural use. The process developed is easy to implement and increases the marketability of the products while also addressing a serious health and environmental challenge. The study took place during the period 2011-2012 in Ghana. The fecal sludge, rich in nutrients and organic matter, was dried and used to produce five different fertilizers (i.e., four formulations of compost and one with gamma irradiated material). Each material was then pelletized using locally constructed machinery. Key operating parameters, such as moisture content (10-55\% in mass), binder type (clay or starch) and concentration (0-10\% in mass), were varied and their impacts on the characteristics of pellets (e.g., amount of fine materials generated, length distribution or stability of pellets, and pellet disintegration rate) were also followed. Given the low analyzing capabilities of developing countries, some simple analytical methods were developed and used to compare pellets produced under different conditions. The results confirmed that the addition of 3\% of pregelatinized starch is recommended during pelletization of fecal sludge-based fertilizers. Applicable moisture contents were also identified per fertilizer type, and were found to comprise between 21 and $43 \%$.
\end{abstract}

Keywords: fecal sludge, pellet, fertilizer, compost, gamma irradiation, agriculture

\section{Introduction}

In many sub-Saharan African countries, large amounts of fecal sludge (FS) from on-site sanitation systems (i.e., non-sewered household and public toilets, latrines, septic tanks, etc.) end up being dumped in the environment without appropriate treatment. This situation contributes to the pollution of water resources and, consequently, has negative impacts on health (e.g., by promoting the spread of diseases, such as cholera and diarrhea) and the environment, especially in and around highly populated zones in urban areas (Mara, Lane, Scott, \& Trouba, 2010). Raw liquid FS typically contains $8.2 \mathrm{~g} / 1$ of nitrogen (N), $1.1 \mathrm{~g} / 1$ of phosphorus (P), $2.2 \mathrm{~g} / 1$ of potassium (K) and $21.3 \mathrm{~g} / \mathrm{l}$ of organic carbon (C) (Asare, Kranjac-Berisavljevic, \& Cofie, 2003). This explains why many farmers, in several developing countries (Asia, Africa or Latin America), are keen to use this readily available material for agriculture. The usual practice in some parts of Ghana involves informal arrangements between farmers and people that empty latrines, who are invited to empty their trucks of FS straight on to the farm during the dry season (e.g., around December). The material is then allowed to dry for 3 to 4 months, before being used for the cultivation of cereal sat the beginning of the farming season (Cofie \& Adamtey, 2009). Although there may be monetary benefits for farmers, this practice raises concerns due to the possible health risks if safe handling and processing procedures are disregarded (Seidu, 2010). Moreover, the sludge itself can only be transported and placed through the septic trucks, which limits its marketing potential. One better option is to sanitize the sludge and produce a safe and easy-to-handle fertilizer material, through a controlled process.

Recently, a process involving the composting of dried fecal sludge (DFS), with or without the addition of organic matter (e.g., market or domestic waste) and enrichment with inorganic fertilizer, was developed (Adamtey, Cofie, Ofosu-Budu, Danso, \& Forster, 2009; Cofie, Kone, Rothenberger, Moser, \& Zubruegg, 2009). These studies confirmed that the resulting products are safe and their use represents a sustainable approach to improving crop production while preventing soil fertility depletion. However, efforts are still needed to increase the densities of the products which are responsible for most of the difficulties that pertain to storage (large space 
required) and transport (high costs involved) (Danso, Drechsel, Fialor, \& Giordano, 2006; Hara, 2001). The powdered form of the products also induces the generation of dust at the time of application.

Pelletization is considered to be a possible solution to these challenges (Alemi, Kianmehr, \& Borghaee, 2010). Usually, this involves the use of mechanical pressure to increase the density of the material while converting it into pellets (Mani, Tabil, \& Sokhansanj, 2004; Lehtikangas, 2001). Typically, for cylindrical pellets $5 \mathrm{~mm}$ in diameter, the final volume is only 50 to $90 \%$ of the original compost (Hara, 2001). Pelletization of fertilizers also contributes to facilitating their broadcasting and application, e.g., making it a dust-free process (Mavaddati, Kianmehr, Allahdadi, \& Chegini, 2010; Hara, 2001). Also, compared to the traditional powdered (non-pelletized) fertilizers, pellets release nutrient at a steady rate and are effective in decreasing soil and nutrient losses from agricultural fields (Siriwattananon \& Mihara, 2008). This is important, given that the residual nutrient effect of pellets on a cropping season might be more significant than with the use of powders.

The objective of the present study was to identify the conditions under which pellets can be produced from sanitized FS-based material, which are obtained either by composting, co-composting with sawdust or gamma irradiation. The study includes the optimization of key operating parameters, such as moisture content, binder type and concentration, to ensure the production of high-quality pellets, i.e., which are stable for handling and transportation, but with the ability to disintegrate in the presence of water.

\section{Materials and Methods}

\subsection{Characterization of Materials}

\subsubsection{Chemical Analysis of Raw Materials, Composts and Pellets}

Total organic carbon, nitrogen, phosphorus and potassium concentrations in the samples were determined using the procedure followed by Adamtey (2010). Determination of the concentrations of heavy metals (iron, manganese, zinc, copper and lead), ammonium $\left(\mathrm{NH}_{4}{ }^{+}\right)$and nitrate $\left(\mathrm{NO}_{3}{ }^{-}\right)$nitrogen is also described in Adamtey (2010). In determining the $\mathrm{pH}$ of the samples, $10 \mathrm{~g}$ of the ground material and $50 \mathrm{ml}$ of distilled water were combined to form a suspension. The suspension was stirred with a glass rod for 25 minutes and allowed to stand for 30 minutes. A pH meter was then used to read the $\mathrm{pH}$ value of the supernatant. The electrical conductivity (EC) of each sample ( $2 \mathrm{~g}$ of the ground material to $10 \mathrm{ml}$ of distilled water) was measured using the EC meter (Jenway PCM3). Each measurement was replicated three times.

\subsubsection{Microbial Analysis of Pellets}

The total coliforms and E. Coli in the samples were determined using Chromo Cult Coliform Agar (from MerckKGaA, Germany). The first step of the process consisted of adding $2.65 \mathrm{~g}$ of the agar to $100 \mathrm{ml}$ of distilled water. The solution was then heated in a bath of water for about 35 minutes. The medium was poured into petri dishes and allowed to solidify. Thereafter, $10 \mathrm{~g}$ of ground dry pellets were dissolved in $90 \mathrm{ml}$ of distilled water previously autoclaved at $121{ }^{\circ} \mathrm{C}$ for 15 minutes (other dilution rates were used when required). A sterile pipette was used to transfer $0.3 \mathrm{ml}$ of the mixture into the petri dishes, which were then maintained at a constant temperature of $37^{\circ} \mathrm{C}$ for 24 hours in an incubator (inverted position). The procedure was replicated at least three times. For each of the pellet samples, the numbers of total coliforms or E. Coli were expressed as colony forming unit (CFU) per gram of dry pellet and average values calculated.

\subsection{Pre-Treatment of Organic Materials}

Five organic materials were individually used for pellet production. They were: 1) irradiated dewatered fecal sludge (I-DFS); 2) composted dewatered fecal sludge (C-DFS); 3) co-composted dewatered fecal sludge with sawdust (C-SDFS); 4) enriched C-DFS (EC-DFS); and 5) enriched C-SDFS (EC-SDFS). Additional details regarding this are provided in the Supporting Information (SI) section.

\subsection{Grinding}

I-DFS, dried C-DFS and dried C-SDFS were ground to reduce the particle size and form a powder [Plate S2 shows a) Raw DFS; b) C-DFS; c) Ground C-DFS]. The grinding machine was constructed by the Council for Scientific and Industrial Research (CSIR), Ghana (also provided the mixer and the pelletizer) and consisted of a hammer mill having a capacity of $450 \mathrm{~kg} / \mathrm{h}$ (specifications: $220 / 380 \mathrm{~V}, 4 \mathrm{~kW}$ motor, 1,470 r/min; outside dimensions: $1 \mathrm{~m}$ length, $0.5 \mathrm{~m}$ width and $1.2 \mathrm{~m}$ height).

\subsection{Enrichment}

To produce the enriched composts, $62 \mathrm{~g}$ and $86 \mathrm{~g}$ of ammonium sulphate $\left(\left(\mathrm{NH}_{4}\right)_{2} \mathrm{SO}_{4}\right)$ were added to each kilogram of the ground C-DFS or C-SDFS, respectively, to increase their respective $\mathrm{N}$ content. For this purpose, the required amount of ammonium sulfate granules was totally dissolved in a reduced amount of water. The 
mixture was then added to the compost and mixed thoroughly with a mixer (capacity: $20 \mathrm{~kg} / \mathrm{batch}$; specifications: $380 \mathrm{~V}, 1.5 \mathrm{~kW}$ motor, $1,390 \mathrm{r} / \mathrm{min}$; outside dimensions: $1.6 \mathrm{~m}$ length, $0.5 \mathrm{~m}$ width, $1 \mathrm{~m}$ height) for 5 minutes to obtain a uniform phase (Plate S3). Hand mixing was performed for small samples $(\leq 4 \mathrm{~kg})$. It is to be noted that I-DFS was not enriched since it naturally has a high $\mathrm{N}$ content (the initial $\mathrm{N}$ content was not lost since it was not composted).

\subsection{Binding Agents}

Preliminary investigations revealed that cassava starch and clay were possible binding materials that can be used for pelletization (Nikiema, Cofie, Asante-Bekoe, Otoo, \& Adamtey, in press). The first step in this study consisted of comparing these two materials, i.e., cassava starch and clay. For this purpose, a 1:1 kaolinite clay and cassava (variety Ankrah) starch were used as binders (concentration: 0-10\% in mass) for pelletization of C-SDFS. Cassava starch (variety Yepesivi) was used in the subsequent experiments (concentration: 0-5\% in mass).

The clay was obtained from Odumase (Eastern Region) in Ghana. After extraction, it was sun-dried, ground and sieved $(500 \mu \mathrm{m})$. For pelletization, clay was dry-mixed with powdered fertilizer before the required volume of water was added. On the other hand, the two starch materials were purchased from the CSIR-Food Research Institute in Accra, Ghana. They were pre-treated before use, either through gamma irradiation or pregelatinization, in order to improve the binding ability of the native starch (Kaliyan \& Morey, 2009). In the present study, the pregelatinization process involved combining the required amounts of water $\left(85 \pm 5^{\circ} \mathrm{C}\right)$ with dry starch under manual stirring. This led to the formation of a paste which, in fact, is a mix of water and pregelatinized starch. It was then integrated into the organic material to produce pellets. On the other hand, the starch irradiation process consisted of subjecting the dry cassava starch to $20 \mathrm{kGy}$ of radiation doses for a duration of two days. This was also performed at the Radiation Technology Centre of the Biotechnology and Nuclear Agriculture Research Institute in Ghana. As in the case of clay, irradiated starch was dry-mixed with the powdered material to be pelletized.

\subsection{Pelletization}

For each test, at least $4 \mathrm{~kg}$ of each fecal sludge material (I-DFS, C-DFS, C-SDFS, EC-SDFS and EC-DFS) was used. They were mixed thoroughly with the desired amounts of starch (irradiated or pregelatinized), clay and water to obtain a homogenous mixture and was used to feed the 380-Vpelletizer locally designed by the CSIR (capacity: I-DFS: up to $80 \mathrm{~kg} / \mathrm{h}$, C-DFS: up to $90 \mathrm{~kg} / \mathrm{h}$, C-SDFS: up to $60 \mathrm{~kg} / \mathrm{h}$, EC-DFS: up to $100 \mathrm{~kg} / \mathrm{h}$, and EC-SDFS: up to $70 \mathrm{~kg} / \mathrm{h}$; and specifications: $380 \mathrm{~V}, 1.5 \mathrm{~kW}$ motor, outside dimensions: $1.2 \mathrm{~m}$ length, $0.5 \mathrm{~m}$ width and $1.4 \mathrm{~m}$ height). To form pellets, the mixture was manually placed in the hopper of the pelletizer and, with the aid of an auger, the sample $(60-100 \mathrm{~kg} / \mathrm{h}$, depending on the material) was forced through a flat metal disc with uniformly distributed holes of $8 \mathrm{~mm}$ diameter. The pellets were cut using a rotating cutter when formed and then manually collected in a plate (Plate S4). The final step consisted of sun-drying the produced pellets.

\subsection{Characterization of Pellets}

\subsubsection{Production Efficiency}

The amount of fine particles generated in the pelletization process is an indicator of the efficiency of the pelletizer as well as the appropriateness of its operating conditions. Fine particles are not desired and their generation should be minimized. In a continuous process, these fine particles should be returned into the grinder (to be re-pelletized), which increases the volume of processed material in an equivalent manner compared to the normal process inflow. To assess the amount of fine particles generated by the process, the dried pellets were initially weighed $\left(\mathrm{W}_{\mathrm{i}}\right)$, then sieved to remove particles that were less than $5 \mathrm{~mm}$ in length and finally weighed again $\left(\mathrm{W}_{\mathrm{f}}\right)$. The percentage of fine particles was calculated from the mix of three production batches (12 dry $\mathrm{kg}$ in total) using Equation (1) while $\mathrm{W}_{\mathrm{f}}$ gave the mass of marketable pellets. The process was repeated twice.

$$
\text { Fine particles[\%] }=\left(\mathrm{W}_{\mathrm{i}}[\mathrm{g}]-\mathrm{W}_{\mathrm{f}}[\mathrm{g}]\right) \times 100 / \mathrm{W}_{\mathrm{i}}[\mathrm{g}]
$$

\subsubsection{Stability}

Stability is defined as the abrasive resistance of a densified product (Kaliyan \& Morey, 2009). The test was intended to simulate the handling challenges that the pellets might go through, from production stage to usage (packaging, transportation and application in a farm). In the absence of standard equipment for these tests, a shaker (HS 501D, IKA-WERKE, 0-300 motions $/ \mathrm{min}$ ) was used. Therefore, $120 \mathrm{~g}$ of pellets were placed into a transparent glass bottle (height $=12.7 \mathrm{~cm}$; diameter: $7.0 \mathrm{~cm}$ ) until it was half full and was then shaken at 300 motions per minute for 1 or 2 hours. For each set-up, three replicates were made. The stability (\%) was estimated using Equation (2), taking into account the mass of pellets before $(120 \mathrm{~g})$ and after shaking $\left(\mathrm{W}_{\mathrm{ft}}\right)$. 


$$
\text { Stability[\%] }=\mathrm{W}_{\mathrm{ft}}[\mathrm{g}] \times 100 / 120
$$

\subsubsection{Disintegration Test}

This test measures the minimum time needed for pellet particles to disintegrate in the presence of water. Fifty (50) pellets (length: 14-18 mm) were placed in a transparent plastic container (height: $14 \mathrm{~cm}$; diameter: $10.8 \mathrm{~cm}$ ) and then $200 \mathrm{~cm}^{3}$ of water was added (Plate S6-a). The time needed for the pellets to disintegrate was recorded. Each test was replicated twice.

\subsection{Data Analysis}

Data collected were subjected to Analysis of Variance (ANOVA) with Design Expert 8 (to assess the influence of key factors and interactions) and GenStat ( $9^{\text {th }}$ Edition) (Least Significant Difference [LSD)] test). More details on standard errors of data are presented in Table S1 (in SI).

\section{Results and Discussion}

\subsection{Pellet Production}

\subsubsection{Use of Irradiated Starch versus Clay with C-SDFS}

This experiment aimed at comparing the performance of the pelletizer when producing pellets using clay (1:1 kaolinite) and irradiated cassava starch (var. Ankrah) as binders. It specifically looked at the role played by the moisture content (i.e., amount of water [in kilograms] per $100 \mathrm{~kg}$ of wet product) of the product being fed into the pelletizer. Indeed, water in an organic product improves its fluidity and can aid in pellet formation through the creation of intermolecular forces. For each material being pelletized, there is an optimum moisture content at which the pellets should be formed to maximize benefits (e.g., low generation of fine particles, high density and low energy consumption by the process) (Reiter, 2008). Insufficient or excess water leads to poor pellet formation. For this experiment, C-SDFS was selected as the test material because it is known to be difficult to pelletize due to its high sawdust content (Hara, 2001). Setting a pelletization conditions with this product would guarantee pelletization with any other material.

At moisture content less than or equal to $30 \%$ (low contents), pellets formed from C-SDFS broke upon contact with the receiving container and those that maintained their shape could barely be handled. Also, the pelletizer easily got blocked with the co-compost material (because of its reduced fluidity), which can lead to excessive heating of the motor of the pelletizer. On the other hand, at moisture content greater than or equal to $50 \%$ (high contents), pellets formed stuck together and excess water drained from the pelletizer. Figure 1 shows the optimal moisture contents identified during pelletization of C-SDFS as a function of the binding material type and concentration. These moisture contents were established taking into account the easiness of pellet production and their physical appearance (e.g., well formed), and ranged between $38 \%$ and $47 \%$. Figure 1 confirms that optimal moisture requirements were highly affected by the binder type and concentration. The highest water requirement was observed when no binding material was used, but as the concentration of the binder increased up to $5 \%$ the water requirement decreased. For binder concentrations between 5 and $10 \%$, the moisture content requirements were stable at 43 and $38 \%$ when using clay and irradiated starch, respectively. These values were in the same order of magnitude as the $40 \%$ value recommended for vegetable compost (Adeoye, 2012; Hara, 2001). However, during this study, it was noticed that the content of water was so critical and that variations as low as $3 \%$ in the moisture content could, in some instances, affect the efficiency of the pelletization process. Figure 1 also shows that, overall, starch required less water when compared to clay. This could be explained by the higher swelling potential attributed to clays. Based on former studies, it was proven that kaolin tends to retain more water than cornstarch (Adeoye, 2012).

Following this study, starch was preferred to clay because clay-based pellets tend to easily disintegrate during storage at room temperature. 


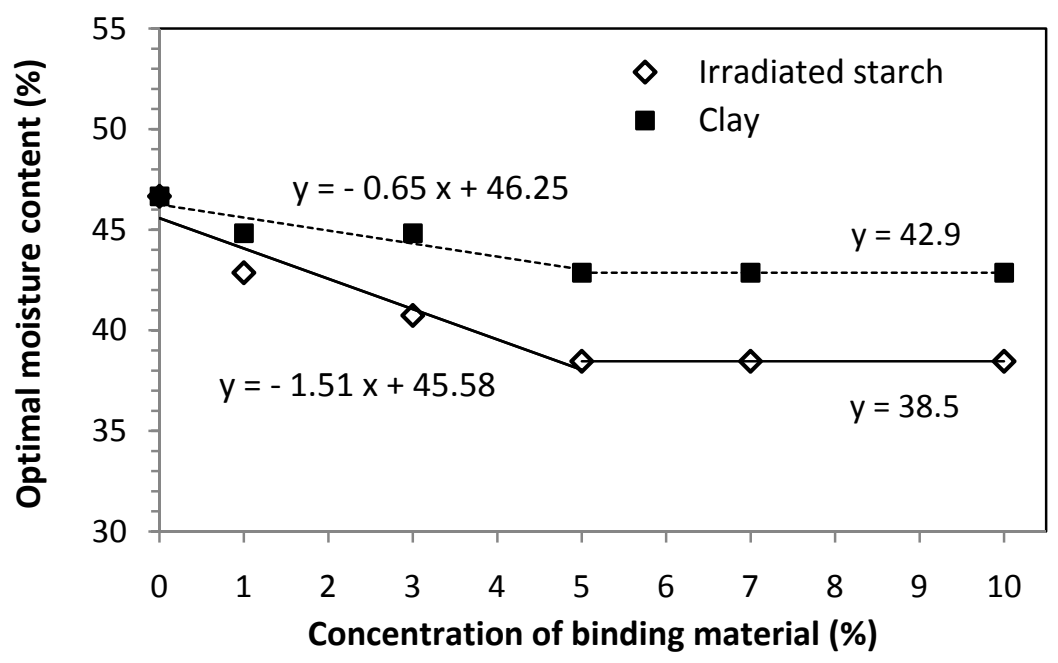

Figure 1. Optimal moisture content as a function of binder type and concentration for C-SDFS

\subsubsection{Use of Starch for I-DFS, C-DFS or EC-DFS}

When using 0 to $5 \%$ of starch (irradiated or pregelatinized), it was established that the acceptable moisture contents were 27 to $31 \%$ for I-DFS or C-DFS and 21 to $25 \%$ for EC-DFS. These values were lower than those required for C-SDFS. Such a difference could be attributed to the nature of sawdust, which has a high water-holding capacity and was the main component in C-SDFS. EC-DFS required the least amount of water for pelletization, probably because of the presence of ammonium sulfate in the product which promoted hydrophobic reactions (http://www.sigmaaldrich.com/). On the other hand, I-DFS and C-DFS required similar water contents, with C-DFS being able to accept higher moisture contents than I-DFS. This minor divergence between I-DFS and C-DFS could be attributed to differences in the chemical structure. Indeed, composting involves aerobic biochemical reactions leading to the decomposition of long-chain organic molecules into bio-stable and shorter molecules. On the other hand, even if irradiation can induce similar reactions, many other chemical reactions (e.g., cross linkages) occur simultaneously (Asare, 2012).

The optimal water requirements were similar for both pregelatinized and irradiated starches. However, a minor discrepancy was noticed for EC-DFS, which required lower water contents than irradiated starch in the presence of pregelatinized starch (Plate S5).

\subsubsection{Production of Fine Particles}

A general factorial design was used to assess the influence of factors such as starch concentration $(0,1,3$, and $5 \%$ ) and pre-treatment method (pregelatinization or irradiation) as well as the moisture content (lowest and highest values) on the production of fine particles (i.e., $<5 \mathrm{~mm}$ in length) when using the various materials (I-DFS, C-DFS and EC-DFS) to produce pellets. Figures 2 and S1 (in SI) present some of the results of this study.

ANOVA allows for concluding that the starch concentration was the most critical factor. Amounts of fine particles decreased, typically by half for C-DFS, when starch was added to the pelletization process; and the higher the concentration, the lower the amounts of fine particles generated. Also, in the presence of starch, the generated amounts of fine particles did not vary much with the moisture content, which increased the resilience of the process. The second most significant factor on the amounts of fine particles generated, as identified by the statistical analysis, was the moisture content. Therefore, appropriate and direct adjustment of this variable is also absolutely needed for good control of the formation of fine particles during pellet production. The type of organic material was the third most significant factor. However, with all the organic materials evaluated, it was possible to generate less than $10 \%$ of fine particles during pelletization by optimizing the first two significant factors, i.e., the binder concentration and the moisture content. 

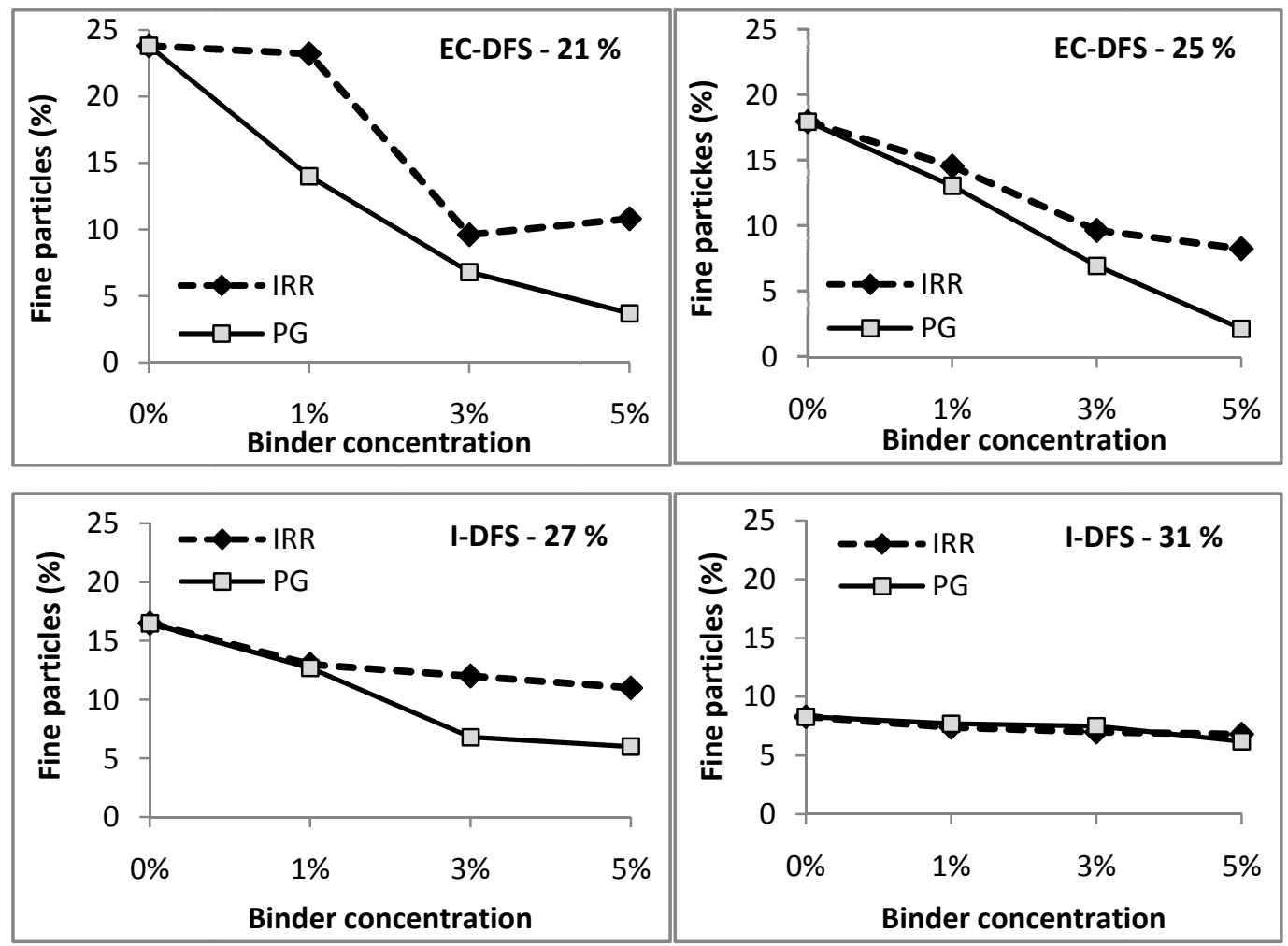

Figure 2. Formation of fine particles for pellet production when using irradiated (IRR) and pregelatinized (PG) cassava starch at various moisture contents

The pre-treatment method applied to the starch was the fifth most significant factor. Indeed, for a given moisture content, pellet batches obtained with the use of pregelatinized starch as binder contained less or the same amounts of fine particles as in those produced with irradiated starch as binder. This could be explained by a higher plasticity attained with pregelatinized starch versus irradiated starch.

Among interactions, the most important one (fourth most significant factor of the model) was between starch concentration and type of material. However, it was easily controlled through direct monitoring, since the individual factors are already statistically significant. Interaction between moisture content and starch concentration was also noticeable. In the presence of higher moisture content, the impact of binding material on the production of fine particles seemed to be minimal, especially for I-DFS. This could be explained by the fact that water itself was acting as a binder. As noted earlier, in the presence of high moisture and pregelatinized starch contents, pelletized material may become sticky and hence get stuck to the cutter of the pelletizer and subsequently to other pellets (Plate S5). However, this observation could not be properly captured as being significant in this ANOVA since fine materials were not produced.

Based on the data and statistical analysis, the classification in order of significance is: Starch concentration $(0-5 \%)>$ moisture content (low or high values; $21-25 \%$ for EC-DFS; $27-31 \%$ for I-DFS and C-DFS) $>$ type of material (I-DFS, C-DFS or EC-DFS) >interaction between starch concentration and type of material > Pre-treatment method applied to starch (pregelatinization or irradiation) >interaction between moisture content and starch concentration.

\subsection{Physicochemical Characteristics of Pellets}

\subsubsection{Size Distribution}

During our study, in all cases, there was not much difference in the diameter of the pellets produced $(7.5 \mathrm{~mm}$ to $7.7 \mathrm{~mm}$ ). This could be attributed to the uniform die hole size of $8 \mathrm{~mm}$. The little variation was the result of the contraction of the pellet which occurred during the drying process. However, operating conditions had a marked effect on pellet length. During this series of experiments, pellet length (after sieving) ranged from $5 \mathrm{~mm}$ to 40 $\mathrm{mm}$. In practice, this wide variation was due to the variable rate at which pellets moved out of the die of the 
pelletizer, which was affected by the fluidity of the pelletized material.

The moisture content seemed to have a negligible effect on the pellet length distribution. This was also true for the binding material's concentration (Figure S2 [in SI]). The key factors that influenced pellet length were the pre-treatment method applied to the starch as well as the type of pelletized material. Indeed, as shown in Figure 3a, pellets produced with C-DFS appeared to be smaller in size than those produced with the other two materials, while EC-DFS generated the longest pellets. As shown in Figure 3b, it is evident that pellets produced with irradiated starch were shorter than those with pregelatinized starch. For example, in the case of EC-DFS pellets formed with $3 \%$ of starch and $21 \%$ of moisture content, $60 \%$ of the pellets produced with the irradiated starch was less than $1 \mathrm{~cm}$ in length, and the corresponding proportion for that produced with pregelatinized starch was only about $25 \%$.

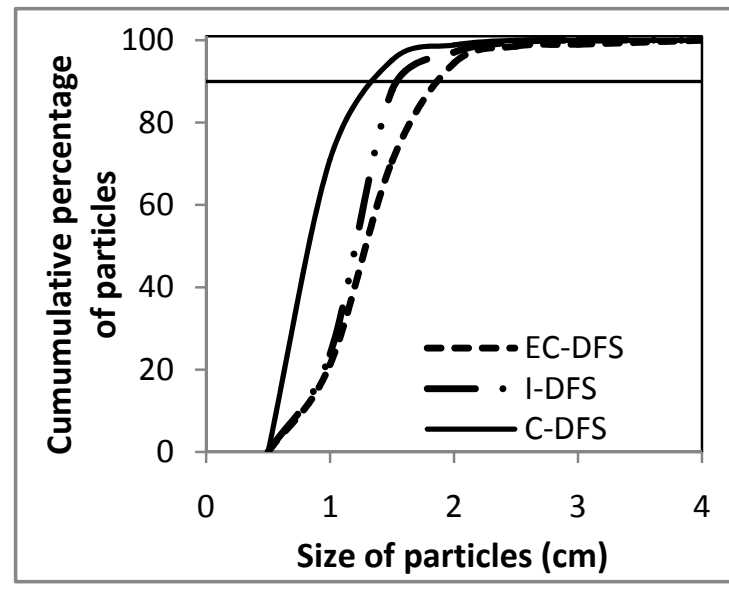

(a)

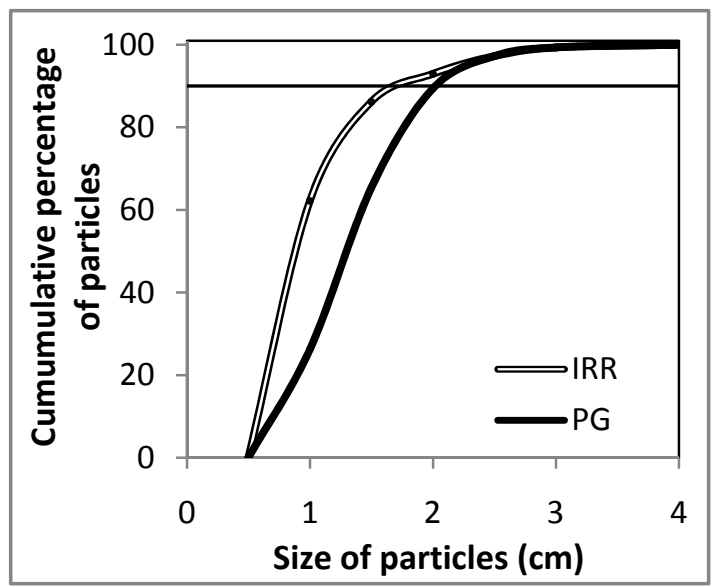

(b)

Figure 3. Effects on size of pellets of: (a) type of organic material (at the lowest moisture content and $0 \%$ binder); and (b) type of starch pre-treatment (EC-DFS; pellets formed with 3\% of starch and $21 \%$ of moisture content)

\subsubsection{Bulk Density}

Table 1 presents the variation in the bulk density for different pellet products. As expected, the bulk density increased with pelletization, i.e., more material could be placed in a typical volume. In the case of I-DFS, the variation was from 0.58 to $0.88 \mathrm{~g} / \mathrm{cm}^{3}(50 \%$ increase) for powder and pellet products, respectively, when no enrichment was performed. For C-DFS, the bulk density was 0.71 and $0.77 \mathrm{~g} / \mathrm{cm}^{3}$ before and after grinding, respectively. Following enrichment and pelletization, bulk density further increased to $0.90-0.92 \mathrm{~g} / \mathrm{cm}^{3}(20 \%$ increase). This confirms that pelletization was an effective way of reducing the volumes of compost by $20-50 \%$ compared to powdered products, which has a high impact on storage and transportation costs.

Table 1. Typical bulk density $\left(\mathrm{g} / \mathrm{cm}^{3}\right)$ before and after enrichment (when applicable) and pelletization with $3 \%$ starch

\begin{tabular}{|c|c|c|c|c|c|c|c|c|c|}
\hline & \multicolumn{2}{|c|}{ I-DFS } & \multicolumn{4}{|c|}{$\begin{array}{c}\text { From raw/powder C-DFS to EC-DFS } \\
\text { pellet }\end{array}$} & \multicolumn{3}{|c|}{$\begin{array}{c}\text { From raw/powder C-SDFS to } \\
\text { EC-SDFS pellet }\end{array}$} \\
\hline & Powder & Pellet-IRR $^{\mathrm{a}}$ & Raw & Powder & Pellet-IRR $^{\mathrm{a}}$ & Pellet-PG ${ }^{\mathrm{a}}$ & Raw & Powder & Pellet-PG $^{\mathrm{a}}$ \\
\hline Minimum & 0.57 & 0.88 & 0.71 & 0.76 & 0.89 & 0.91 & 0.37 & 0.39 & 0.46 \\
\hline Maximum & 0.58 & 0.89 & 0.72 & 0.78 & 0.91 & 0.93 & 0.37 & 0.39 & 0.47 \\
\hline Average $^{b}$ & 0.58 & 0.88 & 0.71 & 0.77 & 0.90 & 0.92 & 0.37 & 0.39 & 0.47 \\
\hline
\end{tabular}

${ }^{\mathrm{a}}$ IRR: irradiated starch; PG: pregelatinized starch; ${ }^{\mathrm{b}}$ Average for three replicates. 


\subsubsection{Chemical Composition}

Table 2 presents the chemical composition of all raw materials used in pellet production. The values were in the same range as those obtained previously under similar conditions $(21 \mathrm{mg} / \mathrm{g}$ of N, $24 \mathrm{mg} / \mathrm{g}$ of P and $5 \mathrm{mg} / \mathrm{g}$ of K) (Adamtey et al., 2009). The raw DFS contained about $27 \mathrm{mg} / \mathrm{g}$ of $\mathrm{N}$. However, content of $\mathrm{N}$ in compost and co-compost decreased to $12-18 \mathrm{mg} / \mathrm{g}$ due to losses that occurred during composting or due to dilution, e.g., when sawdust, less rich in N, is added for co-composting. Gamma irradiation did not induce a significant change in the total nutrient composition, but such pre-treatment increased concentrations of available nutrients. For example, for DFS, before irradiation, $12 \mathrm{mg} / \mathrm{g}$ of the $\mathrm{N}$ content was in the form of $\mathrm{NH}_{4}^{+}$or $\mathrm{NO}_{3}{ }^{-}$. After irradiation, the proportion increased to $15 \mathrm{mg} / \mathrm{g}$. This confirms that organic $\mathrm{N}$ was modified through irradiation to generate inorganic N. Similarly, available P in irradiated material was higher than that of the non-irradiated material.

Table 2. Chemical and physical characteristics of the raw materials used for the production of FS pellet

\begin{tabular}{|c|c|c|c|c|c|c|c|c|c|c|c|c|c|c|}
\hline Product & $\mathbf{C}$ & Total N & $\mathrm{NH}_{4}{ }^{+}-\mathrm{N}$ & $\mathrm{NO}_{3}^{-}-\mathrm{N}$ & Total P & Avail. P & Total K & $\mathrm{Fe}$ & Mn & $\mathbf{Z n}$ & $\mathbf{P b}$ & $\mathbf{C u}$ & pH & EC \\
\hline Unit & \multicolumn{7}{|c|}{$\mathrm{mg} / \mathrm{g}$} & \multicolumn{5}{|c|}{$\mu \mathrm{g} / \mathrm{g}$} & - & $\mu \mathrm{S} / \mathrm{cm}$ \\
\hline DFS & 769 & 26.6 & 8.8 & 2.9 & 12.4 & 0.2 & 6.1 & 4462 & 189 & 346 & 189 & 85 & 7.45 & 1253 \\
\hline I-DFS & 702 & 28.0 & 10.2 & 4.8 & 17.4 & 0.7 & 4.6 & 4124 & 180 & 324 & 224 & 50 & 7.34 & 1695 \\
\hline C-DFS & 651 & 17.7 & 2.3 & 9.8 & 10.8 & 0.2 & 4.4 & 3622 & 148 & 224 & 233 & 72 & 6.62 & 1105 \\
\hline C-SDFS & 713 & 12.0 & 0.5 & 0.3 & 3.3 & 0.1 & 2.5 & 1716 & 68 & 94 & 90 & 47 & 8.66 & 3049 \\
\hline EC-DFS & 651 & 25.7 & 8.8 & 6.1 & 13.8 & 0.2 & 6.8 & 3618 & 140 & 221 & 224 & 71 & 6.62 & 1105 \\
\hline
\end{tabular}

Among the heavy metals, only lead $(\mathrm{Pb})$ showed high concentrations in all the products (up to $233 \mu \mathrm{g} / \mathrm{g}$ ) except for C-SDFS, i.e., more than the maximum allowed value for composts in most known standards (e.g., Canada and United Kingdom $[150 \mu \mathrm{g} / \mathrm{g}]$ or Austria [200 $\mu \mathrm{g} / \mathrm{g}]$ ). Even though the gap was not major with some standard values, this result confirmed the importance of proper monitoring of heavy metals to minimize their risk of long-term accumulation in agricultural land following application of fertilizer pellets.

\subsubsection{Stability}

Tables 3 and 4 present the effect of moisture content as well as binder type and concentration on the stability of pellets after 1 and 2 hours of shaking. According to the statistical analysis, the most significant factor was the duration of shaking time. This means that the higher the shaking time, the higher the risk of producing fine particles as a result of the friction between particles or with the surrounding environment. The type of pelletized material, binding material's concentration and moisture content had a similar impact on the stability of the pellets produced. 
Table 1. Effect of moisture content and binder type and concentration on the stability of pellets after 1 hour of shaking at 300 motions per minute

\begin{tabular}{cccccccc}
\hline & \multicolumn{2}{c}{ Binder } & \multicolumn{2}{c}{ EC-DFS } & \multicolumn{2}{c}{ I-DFS } & \multicolumn{2}{c}{ C-DFS } \\
\hline \multirow{2}{*}{ Type } & \multirow{2}{*}{ Concentration $(\%)$} & \multicolumn{2}{c}{ Moisture content } & Moisture content & Moisture content \\
\cline { 3 - 8 } & & $21 \%$ & $25 \%$ & $27 \%$ & $31 \%$ & $27 \%$ & $31 \%$ \\
\hline None & 0 & 89.0 & 91.0 & 85.4 & 91.6 & 88.3 & 88.9 \\
\hline \multirow{2}{*}{ Irradiated starch } & 1 & 90.4 & 94.2 & 90.0 & 93.3 & 89.9 & 91.2 \\
& 3 & 93.8 & 93.4 & 90.5 & 94.0 & 91.1 & 92.2 \\
& 5 & 95.5 & 94.0 & 92.1 & 92.3 & 92.5 & 91.8 \\
\hline \multirow{2}{*}{ Pregelatinized starch } & 1 & 93.2 & 95.4 & 89.6 & 93.3 & - & - \\
& 3 & 93.8 & 98.9 & 91.1 & 93.3 & - & - \\
\hline & 5 & 99.3 & 97.2 & 90.2 & 91.6 & - & - \\
\hline
\end{tabular}

Table 2. Effect of moisture content and binder type and concentration on the stability of pellets after 2 hours of shaking at 300 motions per minute

\begin{tabular}{|c|c|c|c|c|c|c|c|}
\hline \multicolumn{2}{|c|}{ Binder } & \multirow{2}{*}{\multicolumn{2}{|c|}{$\begin{array}{c}\text { EC-DFS } \\
\text { Moisture content }\end{array}$}} & \multirow{2}{*}{\multicolumn{2}{|c|}{$\begin{array}{c}\text { I-DFS } \\
\text { Moisture content }\end{array}$}} & \multirow{2}{*}{\multicolumn{2}{|c|}{$\begin{array}{c}\text { C-DFS } \\
\text { Moisture conten }\end{array}$}} \\
\hline \multirow{2}{*}{ Type } & \multirow{2}{*}{ Concentration (\%) } & & & & & & \\
\hline & & $21 \%$ & $25 \%$ & $27 \%$ & $31 \%$ & $27 \%$ & $31 \%$ \\
\hline None & 0 & 85.0 & 90.7 & 81.4 & 89.4 & 83.4 & 84.7 \\
\hline \multirow{3}{*}{ Irradiated starch } & 1 & 88.1 & 91.6 & 85.3 & 89.9 & 86.7 & 86.9 \\
\hline & 3 & 92.1 & 91.6 & 86.2 & 91.6 & 87.6 & 87.3 \\
\hline & 5 & 93.6 & 92.5 & 88.9 & 89.2 & 88.8 & 89.9 \\
\hline \multirow{3}{*}{ Pregelatinized starch } & 1 & 90.7 & 92.7 & 86.5 & 90.9 & - & - \\
\hline & 3 & 94.1 & 93.5 & 88.2 & 90.7 & - & - \\
\hline & 5 & 98.9 & 97.1 & 86.3 & 87.8 & - & - \\
\hline \multicolumn{2}{|c|}{$\operatorname{LSD}_{(0.01)}$} & \multicolumn{2}{|c|}{1.0} & \multicolumn{2}{|c|}{0.6} & \multicolumn{2}{|c|}{0.7} \\
\hline
\end{tabular}

With C-DFS and I-DFS, average durabilities were very similar at $87 \%$ and $86 \%$, respectively, after 1 hour and $82 \%$ after 2 hours of shaking. However, EC-DFS durabilities were significantly higher, i.e.,on average, $90 \%$ and $87 \%$ after 1 hour and 2 hours of shaking, respectively. Also, it was noted that increasing the binding material concentration from 0 to $5 \%$ almost linearly increased the stability, on average, from $82 \%$ to $89 \%$, allowing the pellets to stand harsher mechanical conditions. A similar trend was observed in previous studies (Adeoye, 2012). Moisture content was the last critical factor and increase in moisture content, from the lowest to highest tested values, caused the stability of pellets to increase by $4 \%$ on average.

Surprisingly, the pre-treatment method applied to the starch had no significant effect on the stability of pellets. However, its interaction with the type of material had a minor effect on the stability. The most important interactions, statistically, were observed between three main factors, such as moisture content and binding material, type of material and moisture content, and type of material and binder's concentration.

\subsubsection{Disintegration in Water}

Disintegration of pellets is a complex phenomenon usually induced by swelling of molecules and modification of surface tension of particles composing each pellet (Del Gaudio, P. Colombo, G. Colombo, Russo, \& Sonvico, 2005). Solubilization and diffusion of molecules also occur at the same time. All phenomena are affected by $\mathrm{pH}$ and temperature. During the present tests, pellets that have been through stability testing were used. 
Looking at the time needed for full disintegration of each pellet type shown in Figure 4, it was confirmed that the lower the binder concentration the lower the disintegration rate of pellets in water. For EC-DFS, pellet disintegration time ranged between 34 and 120 hours and obviously decreased with increasing binder concentration (Figure 4a). For I-DFS, the same trend was also noticed but to a lower extent, with disintegration times between 39 and 57 hours (Figure 4b). This reveals that, in addition to the previously mentioned phenomena (swelling, $\mathrm{pH}$, etc.), biodegradation of binder contributed to accelerating the disintegration of pellets. Therefore, higher content of starch in pellets, by promoting the growth of the microorganisms during the test, also contributed to hastening disintegration of pellets.

The rate of disintegration was also affected by the type of material the pellets were made of, especially when no binder was added during pelletization (120 hours for EC-DFS versus 57 hours for I-DFS). However, even in the presence of starch, pellets made from I-DFS usually required less time to disintegrate compared to those made from EC-DFS. The explanation of such behavior can certainly be found in the physicochemical properties of each material. I-DFS was more homogenous than EC-DFS, composed of the initial C-DFS to which ammonium sulfate, a hydrophobic compound, i.e., in theory less favorable to swelling (Sigma Aldrich, 2013), was added for $\mathrm{N}$ enrichment purposes (http://www.sigmaaldrich.com/). Also, I-DFS pellets were slightly weaker than EC-DFS pellets (Tables 3 and 4). However, as starch content increased, the difference between the two materials reduced, certainly due to the binder effect. On the other hand, even if pellets formed with pregelatinized starch tended to require less time to disintegrate than pellets containing irradiated starch, the type of pre-treatment of the starch did not influence much the phenomena, except for pellets produced from EC-DFS with 5\% starch.

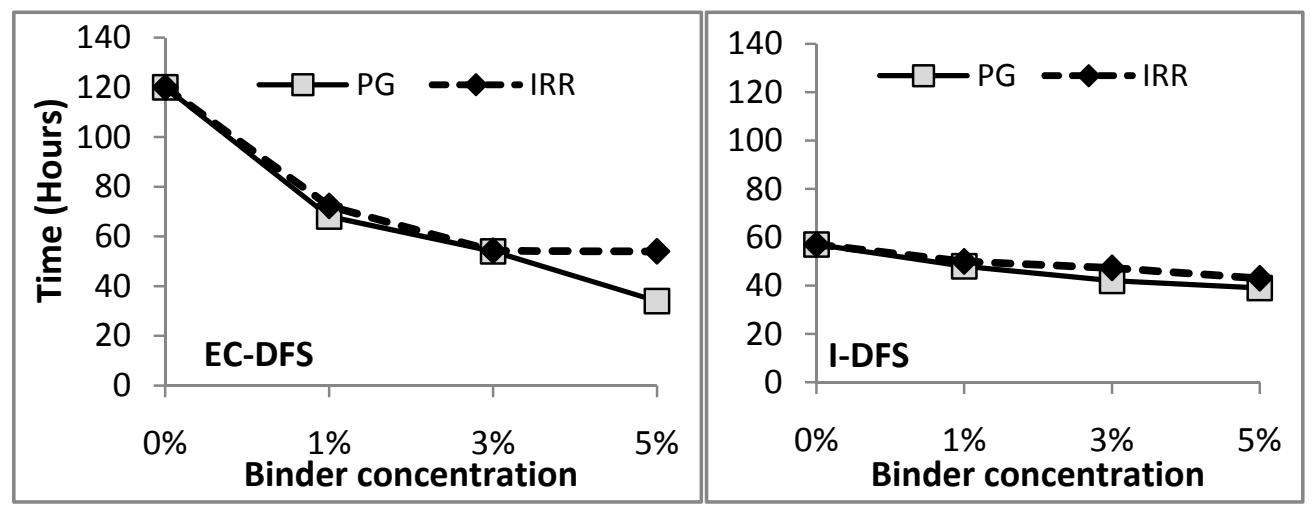

Figure 1. Effect of binder type and concentration on the full disintegration time of pellets: (a) for EC-DFS; and (b) for I-DFS

\subsection{Microbial Characteristics of Pellets}

Microbiological characteristics of the dry pellets produced are presented in Table 5 and were, overall, satisfactory. In pellets, E. Coli concentrations were nil in almost all analyses and never exceeded the threshold given in the WHO guidelines $\left(10^{3} \mathrm{CFU} / \mathrm{g}\right.$ of pellet) (World Health Organization [WHO], 2006). Total coliforms were also quantified, even if no standard limit is provided for this parameter. Average concentrations of total coliforms in EC-DFS pellets were $824 \pm 511$ when using pregelatinized starch and $1370 \pm 1594$ when using irradiated starch. 
Table 3. Concentration ${ }^{\mathrm{c}}$ of coliforms (CFU per g of dry pellets) in various compost materials

\begin{tabular}{ccccc}
\hline & $\begin{array}{c}\text { Date of analysis } \\
(\mathbf{2 0 1 2})^{d}\end{array}$ & June 22 $^{\text {nd }}$ & July 12 $^{\text {th }}$ & Sept 05 $^{\text {th }}$ \\
\hline \multirow{2}{*}{ E. Coli } & C-DFS & 0 & 0 & 0 \\
& EC-DFS & 0 & 0 & 0 \\
& I-DFS & 0 & 0 & $(1 \pm 0.1) \times 10^{3}$ \\
& C-SDFS & $(6.7 \pm 0.6) \times 10^{2}$ & 0 & $(2.2 \pm 0.6) \times 10^{2}$ \\
\hline \multirow{2}{*}{ Total } & C-DFS & $(1.4 \pm 0.0) \times 10^{4}$ & $(1.6 \pm 0.1) \times 10^{4}$ & $(1.5 \pm 0.1) \times 10^{4}$ \\
& EC-DFS & $(1.3 \pm 0.1) \times 10^{3}$ & $(8.5 \pm 0.6) \times 10^{2}$ & $(3.5 \pm 0.1) \times 10^{3}$ \\
& I-DFS & $(4.3 \pm 0.1) \times 10^{4}$ & $(2.7 \pm 1.2) \times 10^{4}$ & $(1.1 \pm 0.2) \times 10^{3}$ \\
& C-SDFS & $(5.5 \pm 0.1) \times 10^{4}$ & $(3.5 \pm 0.1) \times 10^{4}$ & $(3.0 \pm 0.1) \times 10^{4}$
\end{tabular}

${ }^{c}$ Each value presented in this table is an average. Data were measured three times per sample, with 4-7 samples taken per product on each stated day. ${ }^{\mathrm{d}}$ The composting occur in December-March 2012. Pellets were produced in April-June 2012. ${ }^{\mathrm{e}} \mathrm{WHO}$ threshold: $10^{3} \mathrm{CFU} / \mathrm{g}$ of pellet (WHO, 2006).

\subsection{Additional Observations}

Based on the present experiments, the electricity consumption per metric ton of dry pellets produced is 36 (EC-DFS) to 57 (C-SDFS) kWh. This electricity was used for the grinding, mixing and pelletization of the products, but was not required for drying (solar energy) or composting (manual labor). The low energy consumption rate for EC-DFS is a consequence of the higher flow rate achieved by the pelletizer when fed with this material. As a general observation, enriched products required $12-14 \%$ less energy. On the other hand, I-DFS and C-DFS required similar energy for pelletization. In the present operating scenario, the production cost of the pellet plant is, typically, below USD 200 per metric ton in Ghana. The energy cost represents $15-25 \%$ of the pellet production cost while other utilities (such as water, ammonium sulfate for enrichment, cassava starch) constitute some $40 \%$ of the total cost.

On the other hand, pellets containing starch were occasionally attacked by mold. Such a phenomenon occurred during the drying of the pellets at room temperature or during the storage of the pellets in a humid atmosphere (after 2-3 days). The higher the starch content, the more important was this phenomenon. This could easily be avoided later by using an oven to accelerate the drying of the pellets after production and by storing the material in a dry room.

\subsection{Discussion}

The aim of this study was to identify the ideal conditions under which FS-based pellets could be produced. The goal was to maximize the quality of the output (i.e., strength of the pellets to withstand transportation, durability in storage potential and availability of nutrients to a given crop following application to the field) and to minimize the production cost. This later includes minimization of operating volumes or plant size (related to capital expenditure) by reducing losses in the process as well as operating costs through achievement of high production rates (especially by the pelletizer) and minimization of input (water and starch), which are being acquired at a cost.

In the early stage of the research, two binders, i.e., irradiated cassava starch and clay, were compared. Pellets with starch as binder displayed desirable characteristics, especially durability, which led to its selection as binding material. Focusing on cassava starch, experiments confirmed that both pregelatinization and irradiation were suitable pre-treatment methods for the starch. The research later confirmed that such pre-treatment mainly influenced the visual appearance of the pellets (especially the length), but that irradiation had a slightly negative impact on other key properties (e.g., strength). Given that pregelatinization is easier to perform, as opposed to irradiation which is not available in many locations in developing countries, it was preferred to the other option.

Thus, both moisture content and starch concentration were the remaining key factors to optimize. The increase in moisture content was beneficial for the material fluidity, also causing the amount of fine particles generated to be lower and the pellets to be stronger. However, to achieve this, higher amounts had to be processed, causing the 
unit to become more voluminous. To reach a compromise, it is recommended to operate the plant within the ranges provided for each material and to remain as close as possible to the mean values of each range.

Similarly, high binder rates contributed to minimizing the generation of fine particles and were also beneficial for the stability of the pellets. However, this came with a higher cost for the purchase of inputs. Binder rates also affected the disintegration and, consequently, the possible extent of use of the pellets (e.g., for crops that require quick or slow release of nutrients). Ideally, the selection of the adequate binder concentration should be performed taking into account the market behavior (e.g., are users willing to purchase the product even with a certain percentage of fine particles?). Because such information could only be gathered following commercialization of the product, it was decided to fix the starch concentration at the mean level of $3 \%$ at this stage. This decision can also be supported by the observations that 1) strength and fine particle levels were not statistically different on some occasions when the starch levels were 3 or $5 \%$ or were higher at $3 \%$ than at $5 \%$ (Tables 3 and 4); and 2) use of 5\% of pregelatinized starch could generate pellets of a poor appearance (Plate S5).

Availability of raw materials in the region in which production is being carried out and the needs of the markets in the same area should be considered, when attempting to select the more appropriate process. When looking solely at the technological aspect, one could mention, based on the present study, that production of EC-DFS or C-DFS should be favored. Indeed, both can easily be formed everywhere, which is not the case for C-SDFS, EC-SDFS or I-DFS that require availability of sawdust or gamma irradiation equipment. Production of EC-DFS and C-DFS also required the minimum amount of electricity. However, pellets with sawdust as a raw material have higher organic matter content (Table 2), which should be beneficial to the crops (agronomic trials will be conducted in a subsequent study).

There are few documented studies of pellet production from fecal sludge. The only known case is that of Ladepa (South Africa) which involved the use of a machine, sitting in a container when mobility is desired and able to process fecal sludge with more than $20 \%$ of total solids unlike $0.5-5 \%$ in the present study. The difference in moisture content is a great determinant of the actual method to use in FS processing. The unit, which involves the use of medium-wave infrared radiation, is compact and able to process up to 20 tons per hour of raw FS. The process does not involve composting or binder addition and consumes $507 \mathrm{kWh}$ of electricity per ton of pellets produced. The pellets produced are $6 \mathrm{~mm}$ in diameter (Harrison \& Wilson, 2012).

\section{Conclusion}

Excreta are a rich source of essential plant nutrients and organic matter that can be recycled and reused as fertilizer-cum-soil conditioner - an effect not shared by chemical fertilizers and of need in tropical soils. Decomposed excreta improve soil structure, increase water-holding capacity, reduce pests and diseases, and neutralize soil toxins and heavy metals. However, its application has been constrained due to the challenges of handling and transportation over long distances. Within this project, it was hypothesized that converting fecal sludge into sanitized fertilizer pellets would help to address the previously mentioned challenges while enhancing agricultural productivity and contributing to the reduction in environmental and health risk of wastes. To match the expressed product requirements, which varied between cropping systems, the nutrient value was also modified in some cases through blending with inorganic fertilizers, thereby ensuring support for different crop nutrient demands.

Both moisture content and starch concentration greatly affected the amounts of fine particles generated during pelletization as well as the stability of the pellets produced, but had a negligible effect on the pellet length distribution. The material type being pelletized influenced all pellet properties, but can hardly be controlled. Nevertheless, pelletization increased the bulk density (i.e. reduced the required packaging volume) by $20-50 \%$, compared to powdered products. Applicable moisture contents are $27-31 \%$ for C-DFS or I-DFS, $21-25 \%$ for EC-DFS, $38-46 \%$ for C-SDFS and $37-40 \%$ for EC-SDFS. When trying to improve on the binding ability of starch, irradiation, a technique which is not available in many locations in developing countries, did not bring extra benefits compared to pregelatinization which is easy to perform.

Based on the results of this study, the addition of $3 \%$ of pregelatinized starch is recommended during pelletization. In a subsequent phase, it is planned to consider varying the diameter of the pellets and confirm the effect of pellets on crops, following their application in the field.

\section{Acknowledgements}

The authors would like to express their gratitude to the Bill \& Melinda Gates Foundation for funding this research. They would also like to thank all the people who have assisted in collecting information that is reported 
in this paper, including Mr. Isaac Asare (Biotechnology and Nuclear Agriculture Research Institute, Ghana) and Mr. Bright Agbomadzi (intern, International Water Management Institute [IWMI], Ghana office), as well as all the project partners that collaborated in this research study.

\section{References}

Adamtey, N. (2010). Nitrogen enrichment of compost and co-compost for maize (Zea mays L.) cultivation and its effects on the soil environment ( $\mathrm{PhD}$ dissertation, University of Ghana).

Adamtey, N., Cofie, O., Ofosu-Budu, K. G., Danso, S. K., Forster, D. (2009). Production and storage of N-enriched co-compost. Waste Management, 29, 2429-2436. http://dx.doi.org/10.1016/j.wasman.2009.04.014

Adeoye, G. O. (2012). Physico-biochemical analysis of selected binding materials (pp 1-28). International Water Management Institute.

Alemi, H., Kianmehr, M. H., \& Borghaee, A. M. (2010). Effect of Pellet Processing of Fertilizer on Slow-Release Nitrogen in Soil. Asian Journal of Plant Sciences, 9, 74-80. http://dx.doi.org/10.3923/ajps.2010.74.80

Asare, I. (2012). Fundamentals of radiation sterilization (pp. 1-2). International Water Management Institute.

Asare, I., Kranjac-Berisavljevic, G., \& Cofie, O. (2003). Faecal sludge application for agriculture in Tamale, Ghana. Urban Agriculture Magazine, 10, 32-33.

Cofie, O., \& Adamtey, N. (2009). Nutrient recovery from human excreta for urban and peri-urban agriculture, WEDC international conference, Addis Ababa, Ethiopia. Retrieved from http://publications.iwmi.org/pdf/H042722.pdf

Cofie, O., Kone, D., Rothenberger, S., Moser, D., \& Zubruegg, C. (2009). Co-composting of faecal sludge and organic solid waste for agriculture: Process dynamics. Water Resources, 43, 4665-4675. http://dx.doi.org/10.1016/j.watres.2009.07.021

Danso, G., Drechsel, P., Fialor, S., \& Giordano, M. (2006). Estimating the demand for municipal waste compost via farmers willingness-to-pay in Ghana. Waste Management, 26, 1400-1409.http://dx.doi.org/10.1016/j.wasman.2005.09.021

Del Gaudio, P., Colombo, P., Colombo, G., Russo, P., \& Sonvico, F. (2005). Mechanisms of formation and disintegration of alginate beads obtained by prillin. International Journal of Pharmaceutics, 302, 1-9. http://dx.doi.org/10.1016/j.jpharm.2005.05.041

Hara, M. (2001). Fertilizer pellets made from composted livestock manure. Extension Bulletin-Food and Fertiliser Technology, Central Asian Pacific Region, 506, 1-12.

Harrison, J., \& Wilson, D. (2012). Towards sustainable pit latrine management through LaDePa. Sustainable Sanitation Practice, 13, 25-32.

Kaliyan, N., \& Morey, R. V. (2009). Factors affecting strength and durability of densified biomass products. Biomass and Bioenergy, 33, 337-359. http://dx.doi.org/10.1016/j.biombioe.2008.08.005

Lehtikangas, P. (2001). Quality properties of pelletised sawdust, logging residues and bark. Biomass and Bioenergy, 20, 351-360. http://dx.doi.org/10.1016/S0961-9534(00)00092-1

Mani, S., Tabil, L. G., \& Sokhansanj, S. (2004). Evaluation of compaction equations applied to four biomass species. Canadian Biosystems Engineering Journal, 46, 355-361.

Mara, D., Lane, J., Scott, B., \& Trouba, D. (2010). Sanitation and Health. PLoS Medicine, 7, 1-7. http://dx.doi.org/10.1371/journal.pmed.1000363

Mavaddati, S., Kianmehr, M. H., Allahdadi, I., \& Chegini, G. R. (2010). Preparation of pellets by urban compost. International Journal of Environmental Research and Public Health, 4, 665-672.

Nikiema, J., Cofie, O., Asante-Bekoe, B., Otoo, M., \& Adamtey, N. (In press). Cassava starch as a potential binding material for the production of fecal compost pellets in Ghana. Environmental Progress.

Reiter, M. S. (2008). Environmental and agronomic evaluation of value-added nitrogen fortified poultry litter and biosolids fertilizers ( $\mathrm{PhD}$ dissertation, Virginia Polytechnic Institute and State University, University of Arkansas).

Seidu, R. (2010). Disentangling the risk factors and health risks of faecal sludge and wastewater reuse ( $\mathrm{PhD}$ dissertation, Norwegian University of Life Sciences, Norway). 
Sigma Aldrich. (2013). Technical Bulletin, Product information. Retrieved from http://www.sigmaaldrich.com/etc/medialib/docs/Sigma/Bulletin/a5479bul.Par.0001.File.tmp/a5479bul.pdf

Siriwattananon, L., \& Mihara, M. (2008). Efficiency of granular compost in reducing soil and nutrient losses under various rainfall intensities. Journal of Environmental Information Science, 36, 39-44.

World Health Organization (WHO). (2006). WHO guidelines for the safe use of wastewater, excreta and greywater-Vol II.

\section{Supporting Information (SI)}

\section{Pre-Treatment of Organic Materials}

Five organic materials were individually used for pellet production. They are: 1) irradiated dewatered fecal sludge (I-DFS); 2) composted dewatered fecal sludge (C-DFS); 3) co-composted dewatered fecal sludge with sawdust (C-SDFS);4) enriched C-SDFS (EC-SDFS) and 5) enriched C-DFS (EC-DFS). To obtain the DFS, six tankers of fecal sludge from public latrines (retention time at source: 2-4 weeks; average: 2.4 weeks; total solids: $30-50 \mathrm{~g} / \mathrm{L}$ ) and 12 tankers of septage (retention time at source: $1-3$ years; average: 1.6 years; total solids: $5-10 \mathrm{~g} / \mathrm{L}$ ), i.e., in the volume ratio of 1:2, were collected from Madina, Adenta and Ashiaman in the Greater Accra Region of Ghana. Each tanker was approximately $15 \mathrm{~m}^{3}$ in capacity. The drying was performed using a sand filter located at Ashialey Botwe (Plate S1a), which is normally managed by the Tema Metropolitan Assembly (TMA). The drying process took place in September 2011 for duration of 15 days and led to the generation of about $2,100 \mathrm{~kg}$ of dewatered fecal sludge (DFS). This material was then stored in polypropylene bags of 30-40 kg (Plate S1b) and transported in a truck to the composting site within the Biotechnological and Nuclear Agriculture Research Institute (BNARI). The sawdust used in this study was obtained from a timber sawmill at Ofankor on the $15^{\text {th }}$ October 2011.

\subsection{Pre-Treatment Method $N^{\circ} 1$ : Irradiation}

The irradiation process consisted of subjecting the raw DFS to gamma rays. Irradiation normally causes atoms and molecules to become ionized or excited, which leads to the production of free radicals causing the breakage of chemical bonds and/or creation of new chemical bonds and cross-linkages. In a sanitization context, these injure living tissue and deactivate molecules that regulate vital cell processes (e.g., DNA, proteins). Consequently, organisms originally in the treated material become unable to grow or reproduce. For our experiments, $200 \mathrm{~kg}$ of DFS were subjected to $20 \mathrm{kGy}$ of gamma rays for two days. This operating condition is the conventional method applied for sanitization of medical tools within the facility. For this purpose, the DFS was repackaged in polypropylene bags of $20 \mathrm{~kg}$ each. The irradiation operation was performed within the Radiation Technology Center of BNARI which has the required equipment (capacity: currently 42,000 curies; machine type: SLL-02, installed in 1995).

\subsection{Pre-Treatment Method $N^{\circ}$ 2: Composting}

As irradiation is not an available option in every location, normal composting was applied for comparison. In the preparation of C-DFS, a one tonne heap of DFS was formed. The first step of this process was to manually break the DFS lumps into smaller particles, then add the required amount of water to reach a moisture content of about $65 \%$ and to finally form the heap $(0.87 \mathrm{~m}$ in height and $2.8 \mathrm{~m}$ in diameter) (start date: November 18,2011$)$. In the preparation of C-SDFS, 0.27 tonnes of DFS was mixed with 0.53 tonnes of sawdust (SD) and applied a treatment similar to the method mentioned previously (start date: October 17, 2011). The heap formed was $0.9 \mathrm{~m}$ in height and $3.1 \mathrm{~m}$ in diameter. For all heaps, temperatures were monitored daily while turning the heap with a spade and shovel, and moistening (to maintain moisture content of 65\%) was performed twice a week (Plate S1). Under these conditions, the required maturation time was about 60 days for C-DFS and 100 days for C-SDFS. After production, both materials were spread on the platform to be sun-dried to reach a moisture content less than $10 \%$. 


\section{Materials and Methods}

Table S1. Quality control of analytical measurements and data standard error range obtained

\begin{tabular}{|c|c|c|}
\hline Parameter & Size of each sample & Data standard error range \\
\hline Moisture content & 4 dry kg & $<1 \%$ \\
\hline $\begin{array}{l}\text { Production of fine } \\
\text { particles }\end{array}$ & $\begin{array}{l}12 \text { dry } \mathrm{kg} \text { (mix of } 3 \\
\text { production batches) }\end{array}$ & $0.6-1.8 \%$ \\
\hline Stability & $120 \mathrm{~g}$ of pellets & $<0.5 \%$ \\
\hline Disintegration test & $\begin{array}{l}50 \text { pellets (length: } 14-18 \\
\mathrm{~mm} \text { ) }\end{array}$ & $2-5$ hours \\
\hline Bulk density & - & $<0.01 \mathrm{~g} / \mathrm{cm}^{3}$ \\
\hline $\begin{array}{l}\text { Chemical } \\
\text { composition }\end{array}$ & Variable & $\begin{aligned} \mathrm{EC}: & <7 \mu \mathrm{S} / \mathrm{cm} ; \mathrm{C}:<2.7 \% ; \mathrm{pH}:<0.03 ; \mathrm{N}, \mathrm{K}:<0.03 \% ; \mathrm{P} \\
& \text { heavy metals: }<0.01 \% ; \mathrm{NO}_{3}, \mathrm{NH}_{4}-\mathrm{N}:<0.003 \%\end{aligned}$ \\
\hline
\end{tabular}

\section{Results}

\subsection{Production of Fine Particles}

Figure S1 confirms that the binder concentration affects the generation of fine particles by the process. The minimal generation rate for the fine particles is observed for the highest binder concentration tested $(5 \%$ in mass).

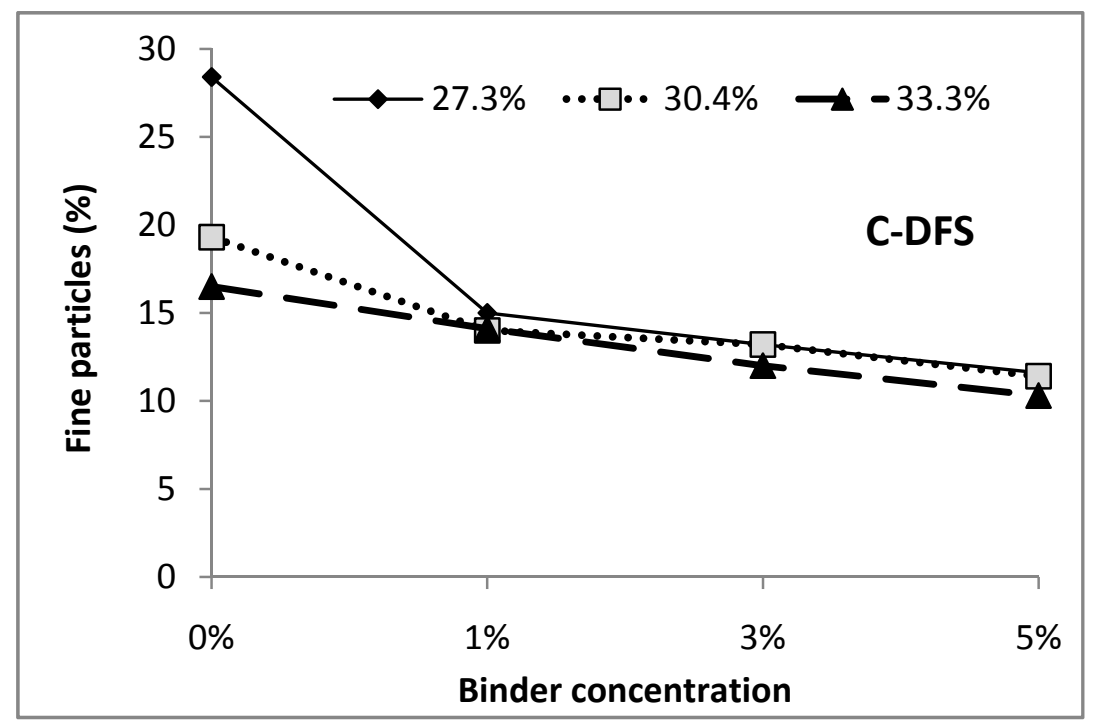

Figure S1. Influence of moisture content on the formation of fine particles as a function of irradiated starch concentration for C-DFS

\subsection{Physicochemical Characteristics of Pellets-Size Distribution}

The moisture content has a negligible effect on the pellet length distribution. This is also true for the binding material's concentration. 


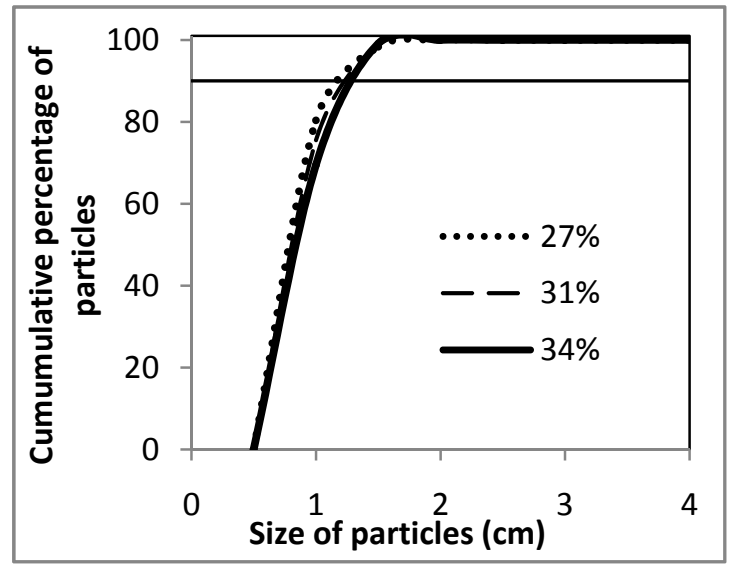

(a)

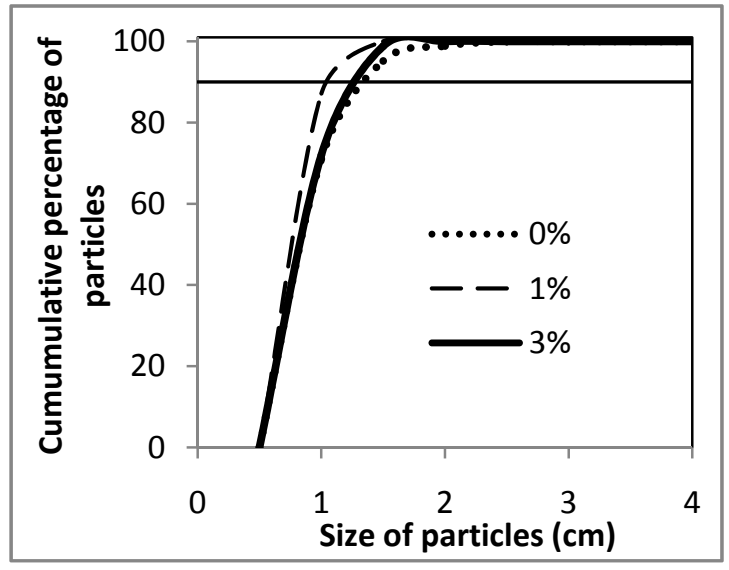

(b)

Figure S2. Effects on pellet size, using C-DFS and irradiated starch of:(a)moisture content (at 3\% of starch); and(b)binder concentration (at $31 \%$ of moisture content)

The moisture content and binding material's concentration have a negligible effect on the pellet length distribution.

\section{Plates-Process and Pellets}

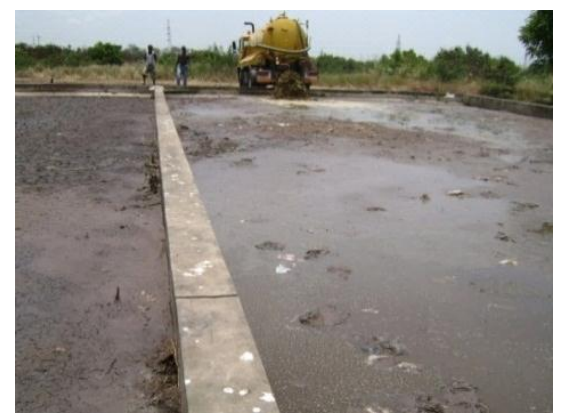

(a)

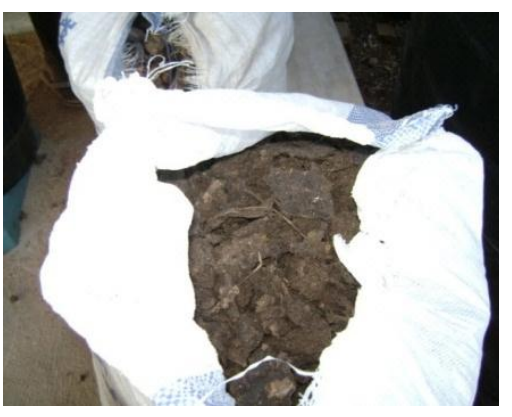

(b)

Plate S1. a) aseptic truck (capacity $=15 \mathrm{~m}^{3}$ ) being emptied on the sand filter, and b) one bag of packaged DFS

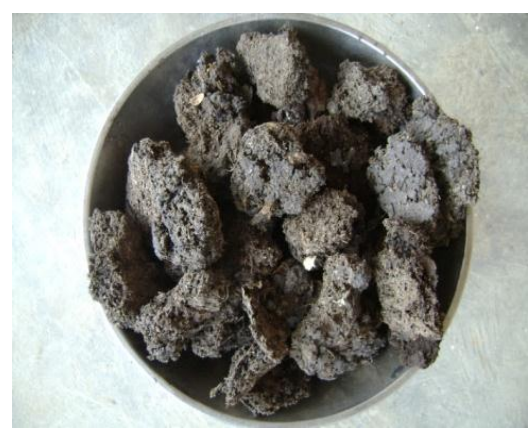

(a)

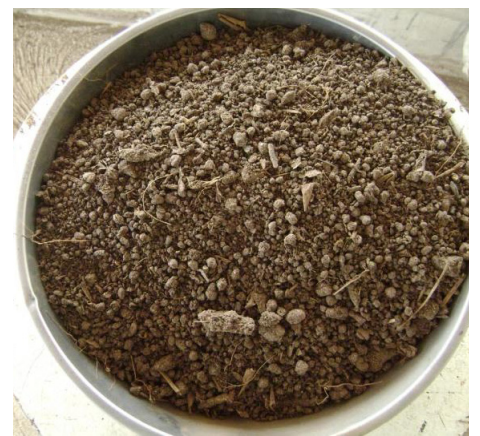

(b)

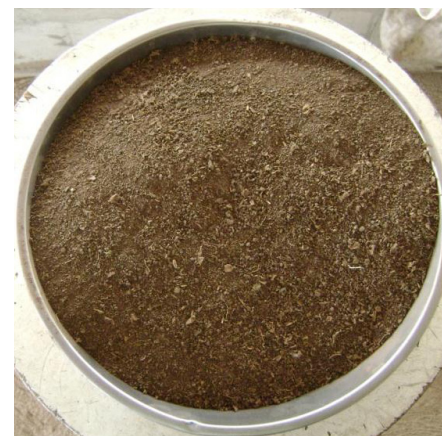

(c)

Plate S2. a) Raw DFS; b) C-DFS; and c) ground C-DFS 

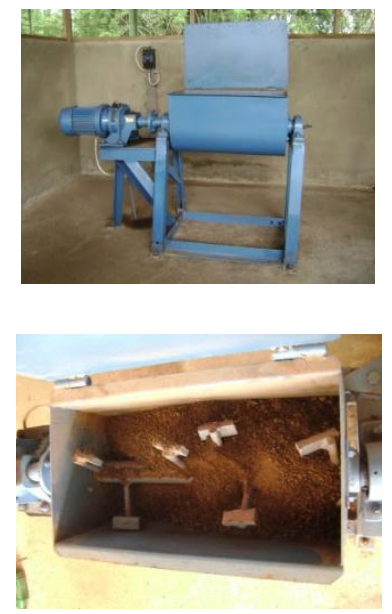

(a)

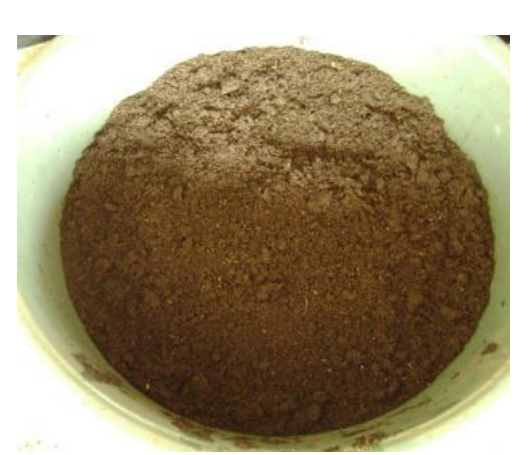

(b)

Plate S3. DFS compost enrichment: a) mixer (side and top views); and b) newly produced EC-DFS

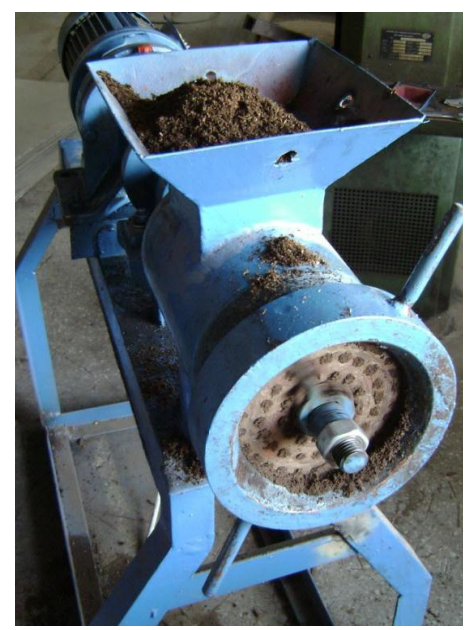

(a)

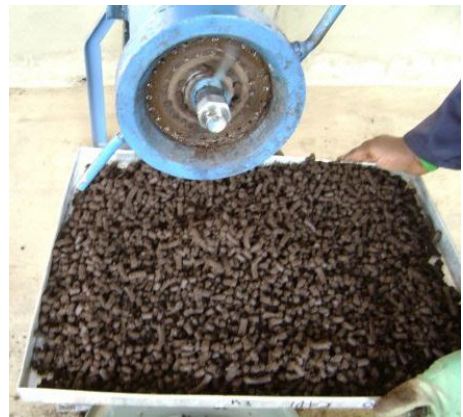

(b)

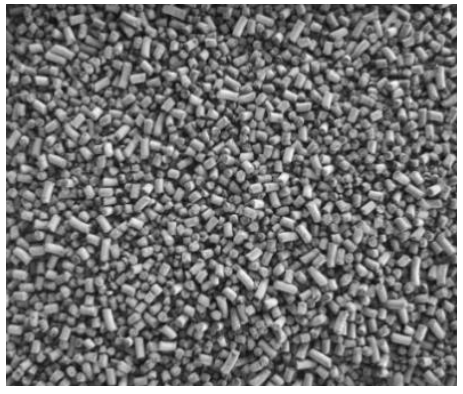

(c)

Plate S4. Pellet production: a) pelletizer being operated; b) newly produced pellets; and c) final pellets (after drying and sieving)

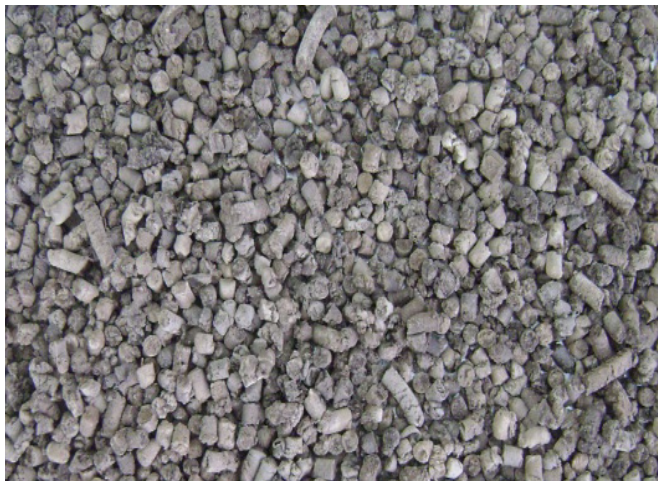

(a)

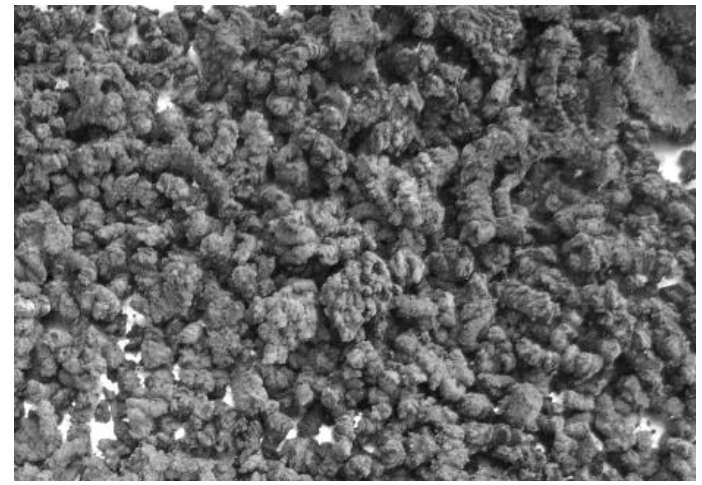

(b)

Plate S5. Pellets formed with EC-DFS under 25\% of moisture content and using 5\% of starch: a) Irradiated; and b) pregelatinized 
At a moisture content of $25 \%$ (high level), the use of $5 \%$ of pregelatinized starch resulted in poor pellet formation; Due to the material being too plastic, cutting of the pellets after their formation was nearly impossible and, at the same time, irradiated starch could still be used.

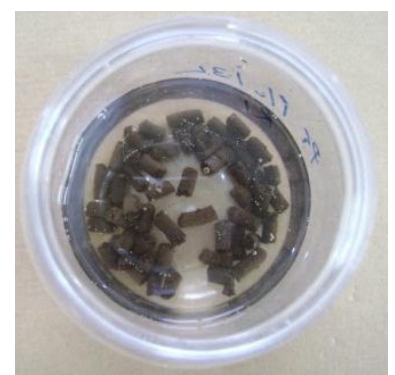

(a)

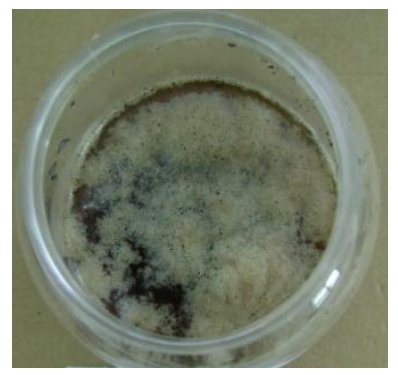

(c)

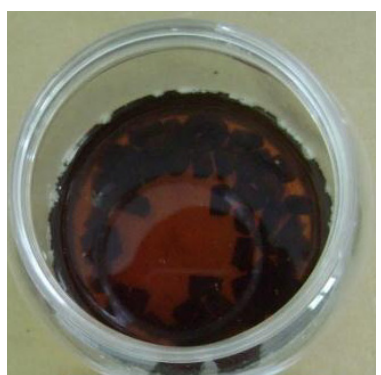

(b)

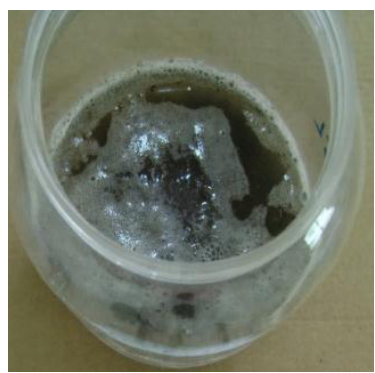

(d)

Plate S6. I-DFS disintegration test: (a) at time $t=0$, after 46 hours in water; (b) $0 \%$ of binder; (c) $5 \%$ of starch-pregelatinized; and (d) $5 \%$ of starch-irradiated

While at $0 \%$ of starch content the liquid was still clear and the pellets were distinguishable after 46 hours, a layer of foamy material identified as fungi developed on top of the vessels containing pellets formed with $5 \%$ starch.

\section{Copyrights}

Copyright for this article is retained by the author(s), with first publication rights granted to the journal.

This is an open-access article distributed under the terms and conditions of the Creative Commons Attribution license (http://creativecommons.org/licenses/by/3.0/). 